\title{
A COMPLEXIDADE EM DIÁLOGO COM A ERGONOMIA E A ENGENHARIA - CONTRIBUIÇÕES DE EDGAR MORIN
}

\author{
THE COMPLEXITY DIALOGUE WITH ERGONOMICS AND ENGINEERING - \\ CONTRIBUTION MADE BY EDGAR MORIN
}

\author{
LA COMPLEJIDAD EN DIÁLOGO CON LA ERGONOMÍA Y LA INGENIERÍA - \\ APORTACIONES DE EDGAR MORIN
}

\begin{abstract}
Professora do Departamento de Engenharia de Produção da Escola Politécnica da Universidade de São Paulo. Pesquisadora Associada do Centro de Inteligência Artificial da IBM/USP/FAPESP, no AgriBio-Food Security. Escola Politécnica da Universidade de São Paulo uiara.montedo@usp.br
\end{abstract}

Uiara Bandineli Montedo

\author{
Tiago Fonseca Albuquerque Cavalcanti Sigahi \\ Graduado em Engenharia de Produção pela Universidade Federal de São Carlos - UFSCar/Sorocaba. \\ Mestre em Engenharia de Produção pela UFSCar/Sorocaba. \\ Escola Politécnica da Universidade de São Paulo \\ tiagosigahi@usp.br
}

Resumo: O amplo pensamento de Edgar Morin compreende a possibilidade de pensar acomplexidade como um olhar que sirva para direcionar as ações no mundo. Nessa perspectiva, discute-se, inicialmente, as contribuições de Morin para as ciências do trabalho, particularmente para a Ergonomia Centrada na Atividade. Em seguida, amplia-se o debate sobre suas contribuições para a engenharia. Morin nos convida a pensar sobre os princípios e limites dos paradigmas sobre os quais tais campos de conhecimento e atuação são construídos. Ele nos oferece a oportunidade de incluir em nosso olhar a dialógica, a ordem e a desordem, as incertezas, as diferentes racionalidades, permitindo trazer ao debate questões fundamentais com relação à vida e à importância do sujeito na sociedade.

Palavras-chave: complexidade; engenharia; ergonomia; paradigma; trabalho.

Abstract: Edgar Morin's broad thought encompasses the possibility of thinking about complexity as a view that serves to direct actions in the world. From this perspective, we initially discuss Morin's contributions to different work sciences, particularly to ActivityCentered Ergonomics. Then, the debate on his contributions to Engineering is discussed. Morin invites us to think about the principles and limits of the paradigms on which such fields of knowledge and action are built. It offers us the opportunity to include in our view the dialogic perspective, order and disorder, uncertainties, different rationalities, allowing us to bring to the debate fundamental questions related to life and the importance of the subject in society.

Keywords: complexity; engineering; ergonomics; paradigm; work.

Resumen: El pensamiento amplio de Edgar Morin compreende la posibilidad de pensar la complejidad como una mirada que sirve para dirigir acciones en el mundo. Desde esta perspectiva, analizamos inicialmente las contribuciones de Morin a las ciências del trabajo, en particular a la ergonomía centrada en la actividad. A seguir, se amplía el debate sobre sus aportes a la Ingeniería. Morin nos invita a reflexionar sobre los principios y límites de los paradigmas sobre los que se construyen tales campos de conocimiento y acción. Nos brinda la oportunidad de incluir en nuestra perspectiva la dialógica, el orden y el desorden, las incertidumbres, las diferentes racionalidades, permitiéndonos traer al debate cuestiones fundamentales relacionadas con la vida y la importância del tema en la sociedad.

Palabras-clave: complexidade; ingeniería; ergonomia; paradigma; trabajo.

Para citar - (ABNT NBR 6023:2018)

SZNELWAR, Laerte Idal; MONTEDO, Uiara Bandineli; SIGAHI, Tiago Fonseca Albuquerque Cavalcanti. A complexidade em diálogo com a ergonomia e a engenharia - contribuições de Edgar Morin. Eccos - Revista Científica, São Paulo, n. 57, p. 1-32, e20269, abr./jun. 2021. Disponível em: https://doi.org/10.5585/eccos.n57.20269. 


\section{Introdução}

As contribuições de Edgar Morin, baseadas na Teoria da Complexidade para os estudos sobre o trabalho e para a engenharia foram se consolidando ao longo do tempo, sobretudo porque os paradigmas complexos permitiram não apenas compreender questões fundamentais da realidade, mas também porque colocaram em xeque pontos de vista baseados na extrema simplificação, usados como pressupostos não apenas para se conceber e gerenciar o trabalho, mas também para guiar os trabalhos de capacitação e de aprendizagem no âmbito da engenharia. A adoção de uma visão baseada nos paradigmas da complexidade traz um novo alento para melhor se compreender a relação do ser humano com o trabalho e para reposicionar os trabalhos no campo da engenharia.

\section{A complexidade como suporte conceitual para a abordagem da ergonomia}

A evolução dos estudos em ergonomia e sua importância para melhor conhecer o que é efetivamente o trabalho humano trouxe uma série de desafios, tanto no que diz respeito ao desenvolvimento de atuações profissionais como para o desenvolvimento de reflexões e conceitos sobre a abordagem da ergonomia propriamente dita. Ao tratarmos da ergonomia, estamos nos situando no campo da Ergonomia Centrada na Atividade que, desde os seus primórdios (GUÉRIN et al., 2001), trata do enigma relativo ao fato de que, por mais que se busque prescrever o trabalho de outros, há sempre uma discrepância com aquilo que enfrentam os trabalhadores para darem conta do que emana do real de suas operações. Assim, é muito comum no campo da Ergonomia Centrada na Atividade fazer uma distinção entre o prescrito e o realizado. A atividade poderia ser definida como o modo pelo qual os trabalhadores usam de si para conseguir atingir os objetivos da produção, utilizando certas ferramentas, baseando-se em certos procedimentos e instruções de trabalho. Isto significa que a atividade de trabalho se desenvolve no tempo e no espaço baseada em prescrições e no que encontram os trabalhadores para conseguir atingir os objetivos. O campo das prescrições pode ser denominado como universo da tarefa, enquanto que a realização dos objetivos de produção se dá pela atividade das pessoas envolvidas diretamente na produção, seja de bens ou de serviços. Há que se levar em conta também que os trabalhadores não podem ser considerados como iguais e imutáveis. O que melhor caracteriza uma população é a sua diversidade. Como, ao longo do tempo, as condições próprias às pessoas variam, tanto por razões fisiológicas como também por causa da aquisição de experiência, de conhecimentos, de saberes-fazer. 
$\mathrm{Na}$ perspectiva que adotamos neste artigo, poderíamos compreender que a atividade seria uma síntese, tanto daquilo que no âmbito do universo da tarefa permite e constrange o trabalhadorcomo, no caso dos trabalhadores, diz respeito às suas condições para que use de si para realizar o que foi previsto na tarefa. Todavia, como aquilo que foi previsto jamais corresponde ao que é necessário enfrentar para se obter os resultados esperados, uma vez que nunca se pode prever exatamente o que vai acontecer e que sempre é possível que algo emerja, é possível afirmar que realizar uma atividade no mundo da produção é sempre dar conta dos mais variados fenômenos que ocorrem. Como estamos tratando de sistemas dinâmicos, onde fenômenos entrópicos, o desordenamento e o reordenamento nas situações estão sempre presentes, a ideia de que a atividade é uma síntese pode ser adotada. Se isto já ocorre em uma linha de produção, onde o principal esforço dos engenheiros e organizadores do trabalho é o de criar uma ordem que permaneça por maior tempo possível nos processos de produção, o que podemos dizer dos sistemas considerados dinâmicos, como a produção contínua? Ou ainda nos trabalhos nos mais distintos sistemas de serviços, onde a própria presença daquele para o qual o serviço se endereça aumenta ainda mais o grau de variabilidade?

Como exemplo da importância da Teoria da Complexidade para se compreender o que é feito numa abordagem da Ergonomia Centrada na Atividade e, também, para enriquecê-la a partir de uma reflexão baseada nos conceitos propostos por Edgar Morin, iniciaremos com a discussão do caso de uma unidade de produção agrícola familiar (UPAF), cujo principal produto é o leite de bovinos (MONTEDO; SZNELWAR, 2008; MONTEDO, 2017).

Nesta situação de produção, fica evidente que, ao desenvolver sua atividade, o agricultor está sempre buscando se antecipar aos fatos que já conhece para evitar que tenha que desenvolver ações de recuperação, uma vez que os mais variados tipos de incidente podem ocorrer. Por meio da análise dos episódios relacionados à amarração dos fardos de palha e feno, é possível ilustrar a preocupação com prevenção de incidentes. Nestas situações, as ações do agricultor buscam evitar que as cordas usadas para amarrar os fardos se misturem com parte das palhas, que irão compor a cama dos animais juntamente com os seus dejetos, que será posteriormente usada como adubo nas áreas destinadas a plantações. Estas ações realizadas quotidianamente têm como objetivo evitar danos aos equipamentos que serão utilizados posteriormente na distribuição das palhas. As palhas que estiverem misturadas com dejetos servirão para compostagem e para o uso como adubo e essas não podem conter as cordas que foram usadas para a amarração dos fardos.

Outros exemplos de antecipação durante o desenvolvimento das atividades do agricultor também servem para ilustrar como é importante que ele tenha uma visão abrangente da 
produção para evitar danos aos equipamentos, retrabalho e perdas na produção. Um exemplo é a preparação dos equipamentos e de baldes de alimento para os animais na véspera, para evitar que tenha que desenvolver tudo ao mesmo tempo no dia posterior. A partir das verbalizações feitas pelo agricultor é possível salientar que este tipo de raciocínio é fundamental para que ele esteja sempre à frente dos acontecimentos, uma vez que, além daquilo que ele previu, há sempre algo que pode acontecer, algo não previsto, algo que desordene o encadeamento de suas ações.

O desenvolvimento de diferentes estratégias, como o exemplo dado, mostra a importância de se desenvolver um pensamento complexo frente a uma realidade composta por inúmeras variáveis, incluindo a presença de seres vivos nos processos de produção; este fato aumenta a incerteza e a aleatoriedade dos fenômenos que precisam ser considerados. Há também outros exemplos de atividades desenvolvidas pelo agricultor que podem ser compreendidas a partir de outros conceitos da complexidade, tais como a recursividade do sistema à sua causalidade complexa e à sua auto-eco-reorganização. No caso das cordas, elas devem ser retiradas para não ficarem junto com os dejetos e ocasionarem acidentes com a distribuição do adubo orgânico, indicando a recursividade que liga a produção de leite originando dejetos animais que servirão de adubo orgânico - com a de milho.

Já para ilustrar a causalidade complexa, é significativa a simultaneidade da exo e da endocausalidade, uma vez que, ao mesmo tempo, ao recolher as cordas dos fardos visando a manter a estabilidade do sistema UPAF, o agricultor está preocupado em prevenir incidentes com o maquinário. Com relação à auto-eco-reorganização, é importante salientar as constantes trocas com o ecossistema no qual está inserido. Estas dizem respeito não apenas à vida - uma vez que o agricultor trabalha com animais e plantas -, ao clima, ao solo, mas também com outros condicionantes do sistema de produção, como os financeiros e sociais.

No caso da relação com os animais, há uma série de ações que são desenvolvidas para induzir comportamentos mais adequados para o manejo. Enfim, ao procurar se organizar para desenvolver o seu trabalho este agricultor encontra graus diferentes de autonomia frente aos diferentes determinantes que precisa considerar para conseguir produzir. Considere-se também as variações que ele precisa ponderar com relação à evolução das suas condições, principalmente como dosa o esforço empreendido para realizar as mais diferentes tarefas e como dá conta do seu cansaço e das mais diferentes necessidades, como a alimentação, hidratação e idas ao banheiro para higiene e para as suas necessidades fisiológicas.

Outro aspecto a se levar em conta é a relação com os seus familiares que, de alguma maneira, também interferem com o seu trabalho. Por exemplo, nas jornadas mais longas e carregadas da primavera, é sua esposa que desenvolve uma série de atividades, como alimentar 
os bezerros e limpar os equipamentos após a ordenha. Como já relatado, é necessário fazer um manejo constante da produção, considerando-se diferentes tipos de determinantes, como os relacionados com fatores externos (exocausalidade), sobretudo as mudanças nas leis como as que dizem respeito às cotas de produção de leite (associadas à gleba de terra) e quais são as margens de manobra que o agricultor dispõe.

Um outro aspecto importante do trabalho do agricultor é a sua inscrição no longo prazo. Há uma série de conhecimentos, que são adquiridos ao longo do tempo, que lhe permitem considerar as variações no cenário da produção, como já citado. A temporalidade é um fato sempre presente, a mudança no ordenamento das tarefas é uma estratégia utilizada para poder antecipar e recuperar incidentes que ocorrem. O próprio posicionamento das instalações e como o agricultor desenvolve as suas atividades permite que ele mantenha sua atenção voltada para os animais, uma vez que é importante acompanhar a evolução do seu comportamento ao longo de toda a jornada de trabalho e, também, considerar que podem acontecer eventos durante a madrugada também. Isto é, há que se manter disponível para acordar durante a noite para agir. A gestão do rebanho inclui também estratégias distintas, como o uso do colostro de uma vaca para alimentar bezerros de outras, organizando assim o seu tempo em relação às necessidades dos recém-nascidos.

Ao pensar a produção de leite, como é o caso deste estudo, a partir dos paradigmas da complexidade, é possível considerar-se a importância tanto da universalidade como da singularidade. A relação dialógica entre esses dois princípios permite compreender o que há de semelhante e aquilo que é específico em uma determinada propriedade agrícola na comparação com outras. Outro aspecto importante das ações desenvolvidas pelo agricultor diz respeito à historicidade das decisões. Qualquer ação tem um efeito de irreversibilidade, tanto no que diz respeito a aspectos físicos como biológicos; as escolhas feitas consideram a experiência acumulada e precisam ser revistas conforme haja mudanças no mercado de carne bovina e leite. É importante interpretar essas ações, a partir dos testemunhos dos sujeitos envolvidos, integrando conhecimentos interligados nas suas ações e decisões, onde a relação entre as partes e o conjunto do sistema de produção é constituinte deste olhar complexo sobre a produção e o trabalho. A imbricação e a recursividade das atividades desenvolvidas em cada subsistema que compõe a produção é um fato bastante significativo, ainda mais quando há uma imbricação de ações de supervisão do rebanho com outras tarefas. Ainda há que se considerar as ações de recuperação dos imprevistos advindos durante a jornada de trabalho, que determinam mudanças no curso da ação. Nesta perspectiva é importante salientar a contribuição do princípio da organização e da auto-organização inerentes ao trabalho do agricultor, uma vez que a cada 
momento, e sobretudo por se tratar de uma interação com seres vivos, o imprevisto pode emergir; isto é, há sempre uma dinâmica de desordenamento e ordenamento que o agricultor precisa dar conta, ou seja, há sempre alterações na organização das atividades. A relação dialógica entre ordem e desordem está sempre presente, uma vez que, como qualquer sistema de produção, trata-se de um sistema entrópico, considerando as diferentes origens com relação às causas dos fenômenos. Trata-se de situações onde a questão da sobre-determinação, isto é, a da múltipla causalidade dos acontecimentos, faz-se visível à luz da complexidade.

Saliente-se também que, ao desenvolver uma ação junto a um sistema de produção agrícola, onde o sujeito agricultor desenvolve uma gama significativa de atividades diversas, é possível reforçar a ideia proposta por Morin quando ele preconiza o princípio de distinção, mas não de separação, entre o objeto ou o ser e seu ambiente. O conhecimento de qualquer tipo de produção onde se reconhece a importância do trabalho vivo, ainda mais quando se trata da produção da vida, incorpora o conceito de que toda organização biológica exige que se considerem suas interações com o ecossistema. Não é possível separar o trabalho do agricultor familiar do ambiente no qual ele vive. O ambiente é parte integrante do sistema, quer pela exocausalidade, quer pelas inter-retroações, quer pelos imprevistos que muitas vezes são desencadeados no ecossistema. Retirar o agricultor de seu ambiente para fins de análise de seu trabalho viria a descaracterizar sua própria atividade.

Como postura profissional, é importante que o ergonomista considere que não se trata de uma mera observação de algo, de um objeto, de um ser reificado. Ao tratar do trabalho humano, é importante que esteja claro um posicionamento onde a observação seja construída com os sujeitos que trabalham, um sujeito humano - situado e datado cultural, sociológica, historicamente. Enfim, este olhar complexo a ser constituído pelo ergonomista tem uma perspectiva antropológica que precisa ser considerada, não só no que diz respeito ao trabalho propriamente dito, mas também a outras facetas da vida, como o contato com a família no próprio ambiente de trabalho - isto faz referência à integralidade do ser e da sua existência.

Enfim, o ergonomista não é neutro, ele interfere no fenômeno observado. No caso, é também significativa a mudança no comportamento das vacas ao perceberem a presença de uma pessoa estranha na sala de ordenha, o que altera, embora não de maneira substancial, o trabalho desenvolvido pelo agricultor. Saliente-se também que a noção de autonomia e a relação com a heteronomia também se fazem presentes. O agricultor possui uma autonomia relativa frente ao seu próprio trabalho, manifestada nas possibilidades de auto-organização que dispõe. Trata-se de uma autonomia relativa, uma vez que há graus de liberdade de ação do agricultor frente ao sistema, ao trabalho e à produção, incluindo as relações com as diretrizes da política 
agrícola adotada em determinado país e nas relações internacionais de produção e distribuição de alimentos, em um determinado momento da história. Isto significa que há diferentes racionalidades inerentes à atividade que ficam evidentes neste tipo de trabalho: há uma necessidade para o agricultor de construir compromissos que permitam tratar de questões que podem ser antagônicas, ou aparentemente antagônicas, como o fato de procurar intensificar a produção para aumentar os ganhos no curto prazo, mas que, no longo prazo, podem trazer consequências negativas para a saúde do rebanho e para a própria saúde do agricultor. Reforçar a importância de que há limitações em qualquer racionalidade e que a incorporação, de modo dialógico, de diferentes perspectivas, faz parte do trabalho do agricultor e pode ser relevada por um olhar complexo do ergonomista.

\section{Um diálogo entre a complexidade e a engenharia}

Na continuidade deste artigo, propomos uma debate mais ampliado entre a Teoria da Complexidade e a engenharia. Note-se que mostramos como a Ergonomia Centrada na Atividade pode ser considerada, a partir de sua abordagem, em se tratando de uma área de conhecimento e de atuação, como pertinente à construção de um olhar complexo, sobretudo porque se trata de uma proposta integrativa e que permite relacionar diferentes informações e conceitos que guardam uma coerência epistemológica com os princípios propostos por Morin. Para Wisner (1995), a ergonomia, assim como a engenharia, podem ser consideradas como “artes", no sentido da profissão, do ofício, "do metier". Trata-se portanto de habilidades, de conhecimentos, de processos de aprendizagem que compõem um conjunto de atribuições que propiciam aos sujeitos maneiras de agir no mundo, considerando-se aspectos da sua história e tradição. A própria origem da palavra arte, derivada do grego Techné e do latim Ars, remete a esta ideia de profissão. Assim, uma das questões derivadas do que foi apresentado neste artigo diz respeito à relação dos pressupostos mais utilizados na engenharia com os pressupostos da complexidade.

Ao menos em seu modelo mais prevalente, o ensino da engenharia reforça a perpetuação de paradigmas clássicos. Trabalhos como os de Minai, Braha e Bar-Yam (2006), Frei e Serugendo (2011) e Heylighen (2015) permitem a caracterização da engenharia clássica a partir do princípio da simplificação-disjunção-redução-exclusão. Por outro lado, no sentido da noção moriniana de paradigma, pode-se questionar sobre a possibilidade de transformá-lo, questionando e rompendo com o processo de perpetuação/absolutização desse tipo de paradigma. 
Estudos nas áreas de educação em engenharia (HAGHIGHI, 2005; JESIEK et al., 2011; PAWLEY, 2019; JOHRI; OLDS, 2014; FINELLI; BORREGO; RASOULIFAR, 2015), filosofia da engenharia (MITCHAM, 1994; MEIJERS et al., 2009; POEL; GOLDBERG, 2010; MICHELFELDER; MCCARTHY; GOLDBERG, 2017;MICHELFELDER; NEWBERRY; ZHU,2017), epistemologia da engenharia (BEDER, 1999; RADCLIFFE, 2006; CHRISTENSEN et al., 2015; LUCENA, 2013; LEYDENS; LUCENA, 2018) e, de maneira geral, aqueles que tratam do trabalho e da prática da engenharia, entre outros, sugerem algumas possibilidades:

- Normalidade: levanta a questão de quais normas e valores sociais são considerados normas culturais dominantes. A partir da concepção da relação entre paradigma e cultura apontada Morin (2011a), pode-se compreender que os valores dos grupos culturais dominantes passam a ser percebidos como normais, isto é, tornam-se pontos de referência para todos os alinhamentos com ou desvio das normas culturais, o que se estende a contextos institucionais, moldando políticas e práticas, inclusive em universidades, empresas e outras organizações (LEYDENS; LUCENA, 2018);

- Superioridade: os valores dos grupos dominantes não são apenas considerados culturalmente normais, mas também são geralmente considerados superiores. Por exemplo, Tonso (2006) e Faulkner (2007) apontam que habilidades como comunicação são muitas vezes retratadas como aspectos "femininos" da engenharia, havendo uma tendência de marginalizá-los durante o processo de capacitação tradicional, em comparação com aspectos considerados "masculinos", como aqueles ligados à técnica (ver também PAWLEY, 2019);

- Viés inconsciente/implícito: os valores dominantes, uma vez normalizados, são internalizados (REUBEN; SAPIENZA; ZINGALES, 2014; LEYDENS; LUCENA, 2018), o que pode ser relacionado aos aspectos infralógico, pré-lógico e supralógico do paradigma (MORIN, 2011a);

- Dualismo técnico-social: na capacitação tradicional ocorre que os problemas de engenharia são muitas vezes apresentados num vácuo social (LEYDENS; LUCENA, 2018), com base na premissa de que os aspectos técnicos e sociais da engenharia habitam domínios distintos e separados (FEENBERG, 2012). Para além disso, essa perspectiva considera não apenas a separação do técnico e do social, mas também a hierarquia entre eles - enquanto as dimensões técnicas são objetivas e 
valorizadas, as sociais são confusas e introduzem ruído ou ambiguidade excessiva em um problema de engenharia claramente definível (CECH, 2014);

- Despolitização: refere-se às ideias de que artefatos tecnológicos são neutros e apolíticos, e de que o engenheiro é um ator neutro, isto é, a engenharia é um domínio puramente "técnico", o que faz com que possa ser realizada objetivamente $(\mathrm{CECH}$, 2013). Assim, a despolitização ocorre quando as dimensões social e política são separadas das (e não reconhecidas como inerentemente intrínsecas às) ações de engenharia (CECH, 2014; LEYDENS; LUCENA, 2018);

- Aceitação acrítica de autoridade: conforme Leydens e Lucena (2018), nos cursos de engenharia geralmente a grande maioria dos problemas é dada, tornando, portanto, a fase de definição do problema irrelevante. Esses problemas préconstruídos e descontextualizados fazem com que estudantes de engenharia internalizem a disjunção entre aspectos técnicos e sociais, e a aceitação acrítica, por parte dos estudantes, decorre da figura do "professor que detém o conhecimento e é uma autoridade no assunto". Os autores acrescentam que a aceitação acrítica de autoridade representa um primeiro passo de um processo de socialização mais amplo, incluindo a aceitação do disciplinamento da mente e do corpo ("comerdormir-estudar"), das emoções/subjetividades, mantendo-as fora dos limites da engenharia, e da própria trajetória universitária, com currículos rígidos que deixam pouco ou nenhum espaço para desvios;

- Estreiteza da visão técnica: o processo de idealização de projetos/soluções/sistemas de engenharia, tanto na formação quanto no trabalho do engenheiro, é muitas vezes realizado sem que se desenvolva um senso de realidade do que é necessário para projetar/construir (e.g., quantidade de esforço físico, disponibilidade de recursos, ferramentas, permissões) e das consequências de ações de engenharia (e.g., condições de trabalho, riscos, meio ambiente, justiça social) (JONASSEN; STROBEL; LEE, 2006; STOJANOV; DOBRILOVIC; ZORIC, 2016; COSTA JÚNIOR; DIEHL; SECOMANDI, 2018). Em outras palavras, o projeto de engenharia passa a ser entendido como algo que pode ser imaginado e resolvido no papel ou na tela do computador (LEYDENS; LUCENA, 2018);

- Exposição ao escrutínio público: de acordo com Beder (1999), a imagem da engenharia como atividade puramente técnica não só se perpetuou no ensino de engenharia, mas também foi reforçada pela comunidade de engenharia. Segundo o 
autor, isso ocorreu devido à percepção de que a natureza social e política das decisões tecnológicas e de engenharia ameaçaria o papel e a influência da figura do engenheiro como especialista, expondo tais decisões ao escrutínio público. Assim, definir um problema de engenharia como estritamente técnico confere a etiqueta de objetividade e esconde convenientemente as escolhas, prioridades e interesses políticos, reduzindo a avaliação à eficácia e o debate aos aspectos técnicos, isto é, aos "especialistas";

- Hiperespecialização: a especialização permite que os especialistas tenham ótimo desempenho em seus compartimentos, favorecendo a cooperação e a produção de conhecimento e elucidação; a hiperespecialização, contudo, é uma especialização que se fecha em si mesma sem permitir sua integração em uma problemática global ou em uma concepção de conjunto do objeto do qual ela considera apenas um aspecto (MORIN, 2017b);

- Cientifização da engenharia: o postulado de que o método científico é a única maneira de conhecer o mundo se torna problemático na engenharia ao excluir outras formas de conhecimento e outros métodos de investigação (RILEY, 2008). Como consequência, ocorre a primazia de certos tipos de racionalidade (instrumental, teleológica), que embora sejam legítimas e desejáveis, não precisam necessariamente excluir outras (comunicativa, axiológica, subjetiva, complexa) (VIZEU, 2005; MORIN, 2010; CILLIERS; PREISER, 2010; TSOUKAS, 2017; GUNTZBERGER; PAUCHANT; TANGUY, 2019);

- Dissolução do sujeito: a cientifização, apoiada no paradigma da ciência clássica e guiada pela busca do conhecimento "objetivo", identifica tudo o que é subjetivo como erro. Analogamente ao método científico, pode-se dizer que o método da engenharia sofre degradação, deixando de ser uma atividade pensante de um sujeito situado cultural, sociológica e historicamente (MORIN, 2010). Tais ideias levam à exclusão do sujeito e, consequentemente, de toda complexidade associada à incompletude da relação entre o objeto (projeto/sistema de engenharia) e o sujeito que o percebe/concebe (engenheiro). De um lado, o sujeito-engenheiro deve praticar uma engenharia neutra, que resulta em sistemas de engenharia (neutros) aos quais, do outro lado, outros sujeitos devem se adaptar, não o contrário.

- Redução do trabalhar: a dissolução do sujeito se desdobra em questões relacionadas ao trabalho. O trabalho, desprovido de pensamento, se transforma em 
gestos, o trabalhador em instrumento ou recurso da produção e o trabalhar em operar. As ciências do trabalho, em especial a Ergonomia Centrada na Atividade (GUÉRIN et al., 2001) e a Psicodinâmica do Trabalho (DEJOURS, 2012; MOLINIER, 2013), embora possuam abordagens teóricas e metodológicas distintas, revelam a prevalência do paradigma da relação concepção-execução como aspectos estanques e separados, e a impossibilidade de trabalhar e produzir seguindo-se estritamente as regras predefinidas, principalmente aquelas prescritas por determinados atores da produção, como engenheiros e gestores. Nessa perspectiva, conforme Sznelwar, Uchida e Lancman (2011), se tudo fosse resolvido pelas prescrições, não seria necessário trabalhar - bastaria operar, no sentido proposto pelas visões mais clássicas e reducionistas de escolas de organização baseadas em premissas tayloristas-fordistas. Segundo Tertre (2013), outros modelos, como aqueles baseados nas ideias do Lean Production e na financeirização da produção, trazem a questão do não reconhecimento do que há de imaterial no trabalho (e.g., competências, conhecimento, conforto, prazer, confiança na qualidade, confiabilidade de informação), que por não serem nem enumeráveis nem mensuráveis, não são contabilizados. Para o autor, esta questão, associada à crescente importância dos serviços e a difusão das tecnologias da informação e comunicação (TIC) na economia, resulta em transformações estruturais tão profundas que os fundamentos das ciências econômicas são colocados em questão. Nessa linha, pode-se pensar que a complexidade também questiona a engenharia clássica em seus fundamentos e, mais que isso, indica um caminho para que ela se transforme e ajude na construção de uma nova economia, isto é, uma economia da funcionalidade ou da cooperação (TERTRE, 2013);

- Questões de saúde: questões do trabalho nos levam à negligência da centralidade do trabalho na construção da saúde. Num mundo em que predomina o princípio utilitário da economia-eficácia (MORIN, 2010), que exige um crescimento sem fim, impondo metas cada vez mais absurdas e defendendo a ideologia de que os homens são seres com capacidade de superação infinita (SZNELWAR; UCHIDA; LANCMAN, 2011), observa-se diversas maneiras de adoecimento psíquico no trabalho. A saúde deixa de ser construção, processo contínuo envolto em incerteza e fundado num corpo-sujeito (DEJOURS, 1986, 2012), e passa a ser reduzida a um estado de bem-estar em contraposição à doença; 
- Relação com o meio ambiente e a sociedade: visões reducionistas da engenharia, do trabalho e da saúde favorecem o desenvolvimento de ações e sistemas de engenharia que colocam em risco as empresas, as pessoas, o meio ambiente, a sociedade. Uma perspectiva da complexidade na engenharia poderia evitar, por exemplo, desde estragos urbanos causados por obras destinadas à melhoria de tráfego, como a pista elevada Presidente João Goulart ou “Minhocão", em São Paulo (PIQUEIRA, 2018), até desastres ambientais, como o rompimento das barragens em Brumadinho (SZNELWAR et al., 2019), que, se foram idealizados e projetados a partir de um princípio da economia-eficácia e da eliminação das incertezas, acabaram resultando, na realidade, na certeza de prejuízos imensuráveis à natureza e à vida.

Após esta apresentação crítica feita com relação aos paradigmas hipersimplificadores que norteiam uma parte significativa dos pressupostos da engenharia clássica, ainda muito presente na contemporaneidade, é importante salientar que esse tipo de abordagem não é uma especificidade sua. Há uma influência desses paradigmas em muitas áreas do conhecimento e, quiçá, podemos afirmar, que exercem uma influência significativa no desenvolvimento atual, sobretudo no que diz respeito às concepções ora existentes com relação à divisão do trabalho na sociedade. Naturalizou-se a ideia de que há aqueles que podem e têm acesso a trabalhos interessantes e desafiadores e aqueles que estariam condenados a exercer tarefas repetitivas e desprovidas de sentido. Por esses motivos, é importante que se discuta no âmbito da engenharia a questão da complexidade e da reintrodução do sujeito como um dos pilares dos sistemas de produção e do trabalho.

\subsection{Rumo à Engenharia da Complexidade?}

O debate sobre as limitações da engenharia clássica não é novo. Há diversas iniciativas internacionais em andamento que explicitam o anseio da sociedade por uma evolução da engenharia e do ensino em engenharia. É o caso, por exemplo, das experiências de diversas universidades em diferentes países onde os programas de engenharia foram direcionados para o enfrentamento dos grandes desafios da engenharia no século XXI, organizados em quatro temas transversais: sustentabilidade ${ }^{1}$, saúde $^{2}$, segurança ${ }^{3}$ e alegria de viver (joy of living) ${ }^{4}$

\footnotetext{
${ }_{1}^{1}$ NAE. Sustainability. Disponível em: youtube.com/watch?v=zwJ5E_EUUF4. 2013. Acesso em: 3 maio 2020

${ }^{2}$ NAE. Health. Disponível em: youtube.com/watch?v=9c05imowc7Q. 2014. Acesso em: 3 maio 2020.

${ }^{3}$ NAE. Security. Disponível em: youtube.com/watch?v=ckHdkOR1OHg. 2013. Acesso em: 3 maio 2020.

${ }^{4}$ NAE. Joy. Disponível em: youtube.com/watch?v=sk3T3_QYrT0. 2013. Acesso em: 3 maio 2020.
} 
(National Academy of Engineering [NAE]). Recentemente, a pandemia causada pelo SarsCoV-2 ou Covid-19 foi colocada no centro dos esforços, perpassando todos os temas (NAE, 2020) e todas as áreas do conhecimento, podendo ser caracterizada como uma crise tripla: comportamental, sanitária e econômica (CONTI, 2020). Outro exemplo relevante é a Escola de Engenharia do MIT, que lançou, em 2016, o New Engineering Education Transformation, iniciativa destinada à pesquisa sobre o estado da arte da educação em engenharia para subsidiar a transformação dos cursos de engenharia da universidade (GRAHAM, 2018). Contudo, como observam diversos autores, os apelos numerosos, reiterados e contínuos por melhorias na educação em engenharia por mais de três décadas sugerem que os investimentos significativos de múltiplas instituições e agências governamentais, juntamente com os esforços de universidades, pesquisadores e professores não surtiram o efeito esperado quanto à profundidade e à amplitude das transformações (MCKENNA; FROYD; LITZINGER, 2014).

Nesse sentido, a Teoria da Complexidade pode servir de ponto de partida para uma reflexão que enriqueça propostas existentes (ou inspire novas) para o desenvolvimento de um pensamento em engenharia baseado na complexidade, dentre as quais:

- A própria definição da complexidade, do latim, complexus, refere-se à ideia do "que é tecido em conjunto", da possibilidade de relacionar, de distinguir sem disjuntar, seja variáveis, conceitos, áreas de conhecimento ou fenômenos relacionados à atividade da engenharia.Como incorporar este tipo de pensamento nas heurísticas da engenharia?

- A incompletude nos alerta para a necessidade de se ter clareza de que não é possível cobrir todas as áreas, temas e variáveis que podem fazer parte do processo de aprendizagem em engenharia.Como desenvolver uma proposta que tenha como pilar fundamental o desenvolvimento da capacidade de pensar, refletir, aprender, criar, conectar? Dito de outra maneira, como preparar profissionais de engenharia capazes não só de resolver problemas atuais, mas de construir e lidar com problemas que ainda não existem?

- A dialógica aponta para a relação ao mesmo tempo antagônica e complementar de fatores relacionados à concepção (complexa) dos fenômenos.Como desenvolver uma abordagem de engenharia que, ao buscar "causar a melhor mudança", leve em conta racionalidades diversas, que não dissolva o singular e o local no universal e os sujeitos no objeto, que incorpore o ponto de vista dos diferentes atores sociais? 
- As ideias de sistema e "sistemicidade" revelam a impossibilidade de separar o objeto do seu meio ambiente.Como incorporar - ao invés de excluir ou negar - a incerteza, a aleatoriedade, a entropia e suas degradações, a subjetividade no processo de projeto em engenharia?

Isso coloca em questão os métodos que se utiliza em engenharia, principalmente no que tange à constituição de uma visão de mundo onde a questão da construção de problemas, considerando-se várias questões integradas, seja a tônica (WISNER, 1995); uma visão que enriqueça também os métodos de aprendizagem ora predominantes, permitindo a compreensão e ampliação do horizonte dos possíveis.

Como observado anteriormente, é preciso enfatizar que não se trata de desabilitar o existente e partir para algo totalmente novo, mas sim encarar o desafio de incorporar novas modalidades de pensamento aos já praticados pela engenharia; não se trata de formar um profissional com uma capacidade maior do que a dos outros, mas sim que seja capaz de pensar além da formatação consagrada (ZILBOVICIUS; PIQUEIRA; SZNELWAR, 2020).

A engenharia da complexidade poderia ser considerada uma revolução paradigmática? Morin nos ensina que as condições para o desaparecimento gradual e para a substituição de um paradigma dominante/absolutizado necessitam de grandes transformações sociais, culturais:

\begin{abstract}
A revolução paradigmática ameaça não apenas conceitos, ideias e teorias, mas também o estatuto, o prestígio, a carreira de todos os que vivem material e psiquicamente da crença estabelecida. Os pioneiros têm de enfrentar, não somente censuras e interdições, mas o ódio. Primeiro desviante e rejeitada, a ideia nova precisa construir-se em um primeiro nicho, antes de poder fortalecer-se, tornar-se uma tendência reconhecida e, finalmente, triunfar.[...]. Vemos e sentimos as tempestades de superfície, não os abalos submarinos. (MORIN, 2011a, p. 290-291).
\end{abstract}

A empreitada da engenharia da complexidade parece, portanto, ter contornos de uma revolução paradigmática. O que se propõe aqui, contudo, é algo muito mais modesto: a reflexão sobre os limites do paradigma clássico da engenharia e a necessidade de aprofundar o debate sobre paradigmas alternativos, como o da complexidade, na esperança de que este possa estimular o surgimento de novas maneiras de pensar e fazer engenharia.

\title{
3.2 O curso de Engenharia da Complexidade na Escola Politécnica da Universidade de São Paulo
}

A Escola Politécnica da Universidade de São Paulo (Poli-USP) aprovou, em 2016, a proposta de criação do curso de Engenharia da Complexidade, elaborada no âmbito do Programa Permanente de Parceria entre a Poli-USP e o Groupe des Écoles Centrale da França 
(ESCOLA POLITÉCNICA DA USP, 2016). Em 2018, a Poli-USP realizou o I Colóquio Internacional de Engenharia da Complexidade ${ }^{5}$, ocasião em que apresentou a proposta do curso em Engenharia da Complexidade para a comunidade acadêmica e a sociedade ${ }^{6,7}$.

Segundo a Poli-USP (2016), o objetivo do curso é prover uma capacitação de profissionais para que se possa responder à natureza dos problemas atuais e, principalmente, os futuros, enfrentados pela sociedade. Para tanto, o curso está fundamentado nas Teorias da Complexidade. Um dos aspectos-chave do curso de Engenharia da Complexidade da Poli-USP é considerar os projetos a serem desenvolvidos em equipes, como pilar central do processo de aprendizagem. O projeto é considerado o principal produto de engenharia e a atividade de projeto é a garantia da capacitação a partir de um olhar complexo, como paradigma para desenvolver uma visão de mundo, método de abordagem, inteligência e formulação de soluções mais amplas e interativas.

Neste curso, entende-se atividade de projeto como modelagem, previsão, procedimentos, análise de riscos, avaliação de incertezas, de interesses envolvidos, conhecimentos necessários, tanto os propriamente científicos como os conhecimentos oriundos da experiência, da prática, da vivência de pessoas envolvidas. Nesse sentido, a atividade de projeto é um permanente exercício de abstração conduzida a partir da realidade com destino à transformação da própria realidade. Pedagogicamente, o projeto é caracterizado como atividade permanente cíclica e iterativa, que liga uma realidade que precisa ser transformada com as teorias científicas que fornecem conceitos como instrumentos de compreensão e de construção de soluções; o projeto deve ser a porta de entrada para a utilização de teorias e os conceitos científicos e, ao mesmo tempo, o seu questionamento e desenvolvimento, uma vez que no real reside nas intenções dos sujeitos (DEJOURS, 2012). Tais ideias permitem associar o conceito de atividade de projeto a princípios fundamentais da complexidade: da retroatividade, da recursividade organizacional, do dialógico, da incerteza e da reintrodução do sujeito do conhecimento em todo conhecimento (MORIN; LE MOIGNE, 2000; MORIN, 2010).

A complexidade, por sua vez, é entendida, neste curso, como a fonte e o fundamento básico e mais profundo a partir do qual deverá ser construída uma visão de mundo por parte dos envolvidos, constituída numa abordagem de engenharia integrativa onde se busca constituir os problemas e construir soluções que se transformarão em projetos que não desconsiderem, $a$ priori, aquilo que, numa epistemologia mais clássica, seria considerado como "ruído". O lema

\footnotetext{
${ }^{5}$ I Colóquio Internacional de Engenharia da Complexidade. Disponível em: https://www.youtube.com/watch?v=3TKFtZD5VGk. Acesso em: 25 maio 2021.

${ }^{6}$ Matéria do Jornal da USP sobre o curso de Engenharia da Complexidade da Poli-USP. Disponível em: https://jornal.usp.br/universidade/poli-apresenta-propostade-curso-de-engenharia-da-complexidade-na-usp/. Acesso em: 25 maio 2021.

${ }_{7}^{7}$ Matéria da revista Exame sobre o curso de Engenharia da Complexidade da Poli-USP. Disponível em: https://exame.com/carreira/um-novo-curso-de-engenhariaesta-sendo-criado-pela-usp/. Acesso em: 25 maio 2021.
} 
do curso é "Projeto desde o primeiro dia", significando o objetivo de construir no(a) aluno(a) uma percepção do mundo como um conjunto de incertezas, e em permanente transformação enfim, complexo.

Assim, busca-se pensar e compreender a realidade atual como uma base de reflexão e não como escopo para a definição da capacitação dos futuros profissionais. O desafio é de se imaginar que esses profissionais atuarão em cenários que ainda não existem e que eles participarão dessa construção do futuro, onde atuarão cada vez mais em cooperação com outros profissionais e em relação com diferentes atores sociais e políticos, que terão um crescente protagonismo. Há espaço para agir tanto no nível da pesquisa no sentido mais acadêmico do termo, isto é, trabalhando com questões básicas no âmbito do desenvolvimento de materiais, equipamentos, processos de fabricação e construção, considerando inclusive uso, operação e pós-uso destes itens, como na resolução de problemas colocados pelas empresas, pelas instituições públicas e pelo Estado. Para tal, é necessária uma sólida capacitação que tenha como base conhecimentos de diferentes disciplinas relacionadas à matemática, à física, à química, às diferentes ciências e tecnologias da engenharia, às ciências da vida, às ciências humanas e sociais, às ciências econômicas, entre outras.

\section{Reintegração do sujeito}

Uma outra contribuição significativa da Teoria da Complexidade é a questão do sujeito no mundo.Isto diz respeito a diferentes campos do conhecimento; nos casos aqui tratados, na Ergonomia Centrada na Atividade e na engenharia, esta questão é central, uma vez que, a partir das visões mais clássicas da ciência, há um risco de reificação dos indivíduos, sobretudo quando se trata do trabalho, onde as visões mais prevalentes no campo da engenharia pouco consideram as características humanas, sobretudo quando se trata de conceber, projetar e gerenciar a produção e o trabalho. No âmbito da Ergonomia, a questão do sujeito também se coloca, pois há um debate bastante profícuo relacionado com o fato de se buscar caracterizar o ser humano no trabalho a partir de diferentes pontos de vista. Um dos debates neste campo de conhecimento diz respeito às contribuições da psicodinâmica do trabalho, a partir de um ponto de vista onde o sujeito poderia ser entendido a partir das propostas da antropologia psicanalítica (SZNELWAR, 2015). Ainda podemos considerar a importância, para os sujeitos, de serem protagonistas do seu trabalho e o protagonismo do trabalho para a produção; neste caso, há que se considerar a centralidade do trabalho para o desenvolvimento das pessoas e dos coletivos, 
assim como o papel fundamental do trabalho para a existência dos sistemas de produção (SZNELWAR, 2015).

As contribuições para o debate sobre o sujeito, advindas de uma visão complexa, são várias. Morin (2015c) entende a estratégia como o método de ação próprio a um sujeito em situação de jogo, no sentido neumanniano do termo, em que, para alcançar os fins, é preciso submeter-se às incertezas e aos acasos do jogo. Contudo, conforme discutido anteriormente, a ciência clássica se fundou na eliminação das incertezas, dos acasos, dos sujeitos, sob o signo da objetividade, ou seja, de um universo constituído de objetos isolados (em um meio neutro) e submetido a leis objetivamente universais (MORIN, 2015a, 2016). Essas ideias reforçam o risco de se reificar as pessoas, tratando-as como meros objetos, como partes de um sistema que foi anteriormente previsto, programado e controlado.

Nessa visão, o objeto existe de maneira positiva, sem que o observador - aquele que concebe - participe da sua construção. Ele é substancial, autossuficiente, possui plenitude ontológica. É uma entidade fechada e distinta que se define isoladamente em sua existência quanto mais isolamos experimentalmente, melhor determinamos a sua realidade "objetiva" (MORIN, 2016).

Ao assumir que qualquer objeto pode ser definido a partir de leis gerais às quais ele é submetido, assim como de unidades elementares pelas quais ele é constituído, exclui-se quaisquer referências ao observador. O sujeito é a deformação, o erro que se deve eliminar a fim de atingir o conhecimento objetivo; ele é dispensado, como perturbação ou ruído, precisamente porque ele é indescritível segundo os critérios do objetivismo (MORIN, 2015a). O mesmo vale para o observado, quando se trata de uma pessoa trabalhando ou coletivo de trabalhadores. Estes são, na perspectiva clássica, sobretudo quando se trata de modelos organizacionais oriundos do taylorismo e do fordismo, considerados como integrantes de uma massa amorfa, onde pouco importa as suas singularidades. O que importa é a sua adaptação ao modelo de produção e à tarefa. Este ponto de vista é radicalmente combatido pelas propostas da Ergonomia Centrada na Atividade, onde o que se busca é adaptar o trabalho às características humanas (WISNER, 1995), e da psicodinâmica do trabalho, onde o trabalhador é considerado em uma perspectiva emancipatória (DEJOURS, 2012).

Contrariamente aos modos de produção e de gestão clássicos, a complexidade se baseia no princípio da incerteza; as incertezas levam à perda irremediável da ideia de que possa existir um ponto de vista supremo, isto é, objetivo, e faz surgir a presença do ponto de vista subjetivo em qualquer visão de mundo - e, dessa maneira, somos forçados a considerar e valorizar o sujeito (MORIN, 2016). 
Ser sujeito implica situar-se no centro do mundo para conhecer e agir. Por isso, o sujeito é egocêntrico 8 (MORIN, 2012). O “eu” se torna todo para si, sendo quase nada no universo. É esse o drama do sujeito: “[...] autotranscende-se espontaneamente, embora não passe de um ácaro microscópico, de uma migalha periférica, de um momento efêmero do universo resistimos como sujeitos ao nosso destino de objetos" (MORIN, 2010, p. 323). Apesar da consciência de que nosso egocentrismo é irrisório, não se pode existir senão como sujeitos egocêntricos (MORIN, 2010). Note-se que, a partir do ponto de vista da antropologia psicanalítica, o sujeito se constitui na presença e na ausência do outro; não haveria um sujeito solipsista, ele sempre é relacional. A discussão sobre o sujeito também pode ser tratada sob o ângulo do protagonismo; no caso das discussões das ciências do trabalho, o sujeito é sempre o centro da sua cena, quem desenvolve a atividade é ele mesmo, a partir do seu corpo, de sua psiquê. Do mesmo modo, há uma referência à importância para o trabalho nos sistemas de produção, isto é, também há um protagonismo do trabalho dos sujeitos para que a produção ocorra, considerando-se as diferentes contribuições dos sujeitos, nos mais variados níveis. Trata-se do protagonismo do trabalho para a produção (SZNELWAR, 2015).

O egocentrismo, contudo, não conduz somente ao egoísmo. O lugar egocêntrico comporta um princípio de exclusão em que ninguém mais pode ocupá-lo; e um princípio de inclusão, que permite que o sujeito se inclua numa comunidade, num "nós", e o coloque no centro do mundo. Paradoxalmente, o princípio de inclusão é necessário ao princípio de exclusão que, pondo-lhe no centro do mundo, permite situar aí o outro (MORIN, 2012).

Morin (2010) acrescenta que o verdadeiro caráter da individualidade não é só a singularidade fenomenal físico-química ${ }^{9}$, mas o fato de que ele é o único para ele computando para si - o indivíduo trata todos os objetos e dados em egocêntrica referência a ele mesmo. Mas o indivíduo é, naturalmente, mais do que um ser pura e simplesmente mais “egoísta”; não é só ele que está no centro do universo, são também seus pais, filhos, congêneres, pelos quais se pode, eventualmente, sacrificar.

Nesse sentido, a concepção do sujeito do ponto de vista da complexidade supera a alternativa e passa à dialógica: reconhece o aspecto original, radical do "Eu" e da relação com o outro (MORIN, 2012). Aqui, Morin aponta outro paradoxo: a objetividade só pode vir de um sujeito.

\footnotetext{
${ }^{8}$ Morin (2015c, p. 140-152) discute a noção de Ego no âmbito da psicanálise. Segundo o autor, esta deve ser concebida como uma ciência da psique, sendo seu objetivo principal a concepção de uma teoria do aparelho psíquico e, no centro dessa teoria, está o Ego, ou seja, o sujeito. Morin acrescenta que, no seu princípio, a psicanálise freudiana é uma ciência do complexo - não somente no sentido banalizado do termo ("eu tenho complexos") -, mas sobretudo no sentido da complexidade bioantropossocial. Assim, o sujeito é o produto e o centro de uma dialógica complexa bio-sócio-individual. Os complexos do sujeito são nós górdios psicoafetivos que alimentam todo pensamento, inclusive racional e científico. Morin também explora com maior profundidade contribuições de outros autores da psicologia e da psicanálise (e.g., Jung, Lacan) e temas/tópicos/conceitos (e.g., teoria da personalidade, pulsão, sublimação, libido, arquétipo, etc.).

${ }^{9}$ Morin (2010, p. 323) se refere à singularidade dos indivíduos no nível imunológico.
} 
O ponto capital é que cada sujeito pode considerar-se, ao mesmo tempo, como sujeito e como objeto e objetivar o outro enquanto o reconhece como sujeito. Infelizmente, é capaz de parar de ver a subjetividade dos outros e considerá-los somente como objetos [...].Para conhecer o outro [...]deve-se percebê-lo objetivamente, estudá-lo, se possível, objetivamente, mas também se deve compreendê-lo subjetivamente. O desenvolvimento de um conhecimento objetivo do mundo deve avançar junto com um conhecimento intersubjetivo do outro (MORIN, 2012, p. 80).

Morin (2017b) propõe, então, que o sujeito apareça na reflexão sobre si mesmo e conforme um modo de conhecimento intersubjetivo, de sujeito a sujeito, que podemos chamar de compreensão. É neste ponto, como observado anteriormente, que o problema do sujeito não é um problema de "subjetividade" no sentido deteriorado do termo que implica contingência e afetividade, mas sim o do questionamento de si sobre si mesmo, sobre o outro, sobre a realidade e a verdade (MORIN, 2016).

Para chegar à noção de sujeito, segundo Morin (2015c), é preciso pensar que toda organização biológica necessita de uma dimensão cognitiva - nada na atividade humana escapa à computação ${ }^{10}$, ao mesmo tempo que não pode ser reduzida a ela. Conforme Morin (2010), há uma relação dialógica entre a subjetividade bacteriana e a humana. Num sentido, não há nenhuma relação, porque a bactéria apenas computa, não cogita, ou seja, é um sujeito sem consciência. Em outro, como assinalado anteriormente, há uma relação radical a partir do momento em que ser sujeito é pôr-se no centro do universo - essa estrutura egocêntrica autorreferente é a qualidade fundamental do sujeito (MORIN, 2012).

A ideia de sujeito origina-se, portanto, no ser vivo mais arcaico, mas não se reduz a ele. Desenvolve-se na animalidade, com a afetividade e, no homem, aparece o sujeito consciente (MORIN, 2010). Do cômputo ao cógito, as operações associativas e dissociativas tomam a forma lógica de conjunção, disjunção, afirmação, negação, condição, comutação, distribuição, etc. A partir daí os enunciados e proposições são formulados, analisados, formalizados, em consideração ao verdadeiro e ao falso (MORIN, 2015c) - e é aí que se pode colocar a questão acerca do sujeito: a partir de quais racionalidades, princípios, paradigmas, o cômputo se desenvolve em cógito?

Chega-se, então, à noção complexa de autonomia. Conforme Morin (2017b), do ponto de vista da complexidade, autonomia não é mais uma liberdade absoluta, emancipada de qualquer dependência, mas uma autonomia que depende de seu meio ambiente, seja ele biológico, cultural ou social. Assim, um ser vivo, para salvaguardar sua autonomia, trabalha, despende energia e deve, obviamente, abastecer-se de energia em seu meio, do qual depende.

\footnotetext{
${ }^{10}$ Morin (2017b, p. 120) afirma que essa dimensão cognitiva pode ser chamada de computacional. A computação é o tratamento de estímulos, dados, símbolos, mensagens, que nos permite agir dentro do universo exterior, assim como de nosso universo interior, e conhecê-los. Essa computação do ser individual é a computação que cada um faz de si mesmo, por si mesmo e para si mesmo. O cômputo é o ato pelo qual o sujeito se constitui, posicionando-se no centro de seu mundo para lidar com ele, considerá-lo, realizar nele todos os atos de preservação, proteção, defesa, etc.
} 
Quanto a nós, seres culturais e sociais, só podemos ser autônomos a partir de uma dependência original em relação à cultura, a uma língua, a um saber.

A autonomia, portanto, não é possível em termos absolutos, mas em termos relacionais e relativos (MORIN, 2017b). Dito de outra maneira, há uma relação dialógica entre autonomia e dependência: quanto mais autônomos somos, mais dependentes somos de um grande número de condições necessárias à emergência de nossa autonomia (MORIN, 2010).

De acordo com Morin (2010), julgou-se durante muito tempo que a noção de sujeito era metafísica, porque parecia ligada às ideias de liberdade/autonomia e de afetividade/sentimento, que exclui toda atitude científica e, portanto, impede que se encontre a verdade.

Morin (2015c) propõe, então, distinguir a ideia de verdade do sentimento da verdade. A ideia de verdade corresponde a uma resolução de alternativa verdadeiro/falso sem que necessariamente o sujeito seja envolvido ou afetado; ele formula a ideia de verdade nos cálculos, percepções, observações, sem sentir-se implicado. Já o sentimento de verdade traz a dimensão afetiva/existencial para a ideia de verdade e pode tanto se apropriar da ideia de verdade quanto lhe obedecer; liga-se à ideia de verdade não somente quando estão em jogo os nossos interesses e problemas pessoais, mas também quando nos colocamos nos grandes problemas da natureza do real.

O sentimento de verdade é inseparável do sentimento de certeza, que se deve também distinguir da ideia de certeza. Esta, como a ideia de verdade, pode ser indiferente ao sujeito. $\mathrm{O}$ sentimento de certeza, em contrapartida, comporta uma resposta à angústia da incerteza e o implica pessoalmente.

A necessidade de verdade e a necessidade de certeza recorrem uma à outra. Assim, do ponto de vista da complexidade, a necessidade de verdade deveria primar em relação à de certeza e correr o risco de contradizê-la; o que ocorre, porém, com mais frequência, é que a necessidade de certeza submerge e cega a necessidade de verdade (MORIN, 2015c).

O problema do sujeito é, portanto, compreender o que é compreender (MORIN, 2017a), na relação ambivalente com o outro e consigo mesmo. Todo conhecimento comporta aspectos individuais, subjetivos; as ideias que possuímos nos possuem; o conhecimento humano não consegue prescindir do sujeito, mas deve lutar vitalmente contra o egocentrismo; tem necessidade vital de afetividade (prazer em conhecer, desejo imperativo pela verdade), mas precisa lutar vitalmente contra ela, pois extravia e falseia a cientificidade que a suscitou (MORIN, 2015c).

As propostas da complexidade com relação ao sujeito trazem contribuições para as ciências do trabalho, no caso, a Ergonomia Centrada na Atividade, mas também para a 
psicodinâmica do trabalho. Um ser humano dotado de consciência, de história, de uma perspectiva de unicidade reforça a importância dos sujeitos no mundo da produção. Acrescentando-se às propostas de Morin aquilo que também emerge do universo do inconsciente, como considerado pela psicanálise, é possível se buscar uma compreensão bem mais abrangente do que seria o trabalho na sociedade e a sua importância para o desenvolvimento dos sujeitos, dos coletivos, das empresas e, mesmo, da própria cultura. Trabalhar também é produzir cultura em toda sua abrangência. Essas questões são diretamente tratadas pela psicodinâmica do trabalho. Dejours (2012) usa o termo Kulturarbeit para ilustrar.

\section{Discussão final, conclusões e perspectivas}

\subsection{Um olhar}

Um dos principais pressupostos que integram o amplo pensamento de Edgar Morin propõe que a complexidade seja compreendida como um olhar (MORIN, 2016). Para ele, a questão do método está relacionada a uma busca, a algo que permita não apenas constituir um olhar, mas que sirva para direcionar as ações no mundo. É nesta perspectiva que entendemos as suas contribuições tanto para a Ergonomia Centrada na Atividade como para a engenharia. Trata-se de constituir um olhar que se constituirá no exercício do desenvolvimento, constituindo-se num método a partir de uma experiência guiada por um olhar complexo. Portanto não se trata da aplicação de um receituário para compreender o que se passa no trabalho ou para projetar, implantar e gerenciar algo dentro do âmbito da engenharia. Morin ressalta que, intrínseco ao conceito método, está a noção de caminhada; na perspectiva da complexidade, trata-se de iniciativa, de estratégia, de invenção, de arte; enfim o método é parte integrante e integrativa da atividade de pensar dos sujeitos. Um método, na perspectiva da complexidade não teria como pressuposto nem como objetivo obedecer a um princípio de ordem (eliminando a desordem), de clareza (eliminando o obscuro), de distinção (excluindo o sujeito, a antinomia), ou seja, obedecer a um princípio que liga a ciência ou o conhecimento científico à simplificação lógica. Ao contrário, trata-se de ligar o que estava disjunto a partir de um princípio de complexidade, onde a multidimensionalidade é integrada. (MORIN, 2016).

$\mathrm{Na}$ proposta de Morin, não se trata de contestar o conhecimento "objetivo"; pelo contrário, trata-se de não só conservar absolutamente esta objetividade, mas também de integrála a um conhecimento mais amplo e refletido, de complementá-la para enfrentar o real, uma vez que esta concepção mais clássica, inerente ao cartesianismo e a tudo que dele derivou não é 
suficiente para conceber a diversidade dos fenômenos e o devir aleatório do mundo (MORIN, 2010, 2016).

A contribuição de Morin com relação ao reconhecimento da necessidade de desobedecer ao princípio da redução/disjunção para a emergência de um modo de pensamento complexo é central até porque o pensamento complexo deve investir no que não foi pensado, para repensar a estrutura de nosso pensamento, para possibilitar não apenas aprender, mas, sim, reaprender a aprender a reorganizar o nosso sistema mental (MORIN, 2011b, 2016).

Morin não propõe refundar a ciência, unificar as ciências; não propõe uma teoria unificada da complexidade que abarcaria todas as outras, ou um método tradicional; também não nega a ciencia clássica ou o conhecimento "objetivo". Ele se apoia na ideia de que "[...] o único conhecimento válido é o que se alimenta de incerteza e o único pensamento que vive é o que se mantém na temperatura da sua própria destruição" (MORIN, 2016, p. 39).O pensamento complexo utiliza a lógica clássica, os princípios de não-contradição, de dedução, de indução, mas conhece seus limites, e sabe que, em certos casos, é preciso transgredi-los - "[...] o pensamento complexo não é o contrário do pensamento simplificante, ele o integra" (MORIN; LE MOIGNE, 2000, p. 212).

\subsection{Uma ergonomia}

A Ergonomia Centrada na Atividade é uma abordagem capaz de colocar em evidência a complexidade do sistema formado pela UPAF, como também é pertinente sua associação à Teoria da Complexidade, de forma a construir a inteligibilidade da atividade de trabalho, através da explicação complexa (SIGAHI; SZNELWAR, 2021).

A atividade de trabalho tem uma função integradora na situação de trabalho: "[...] as dimensões técnicas, econômicas, sociais do trabalho existem apenas através da atividade que as põe em ação e as organiza" (GUÉRIN et al., 2001, p. 26). Assim, por meio da leitura complexa da atividade de trabalho, a Análise Ergonômica do Trabalho (AET) consegue colocar em evidência a complexidade do sistema, a complexidade da situação de trabalho e a gestão desta complexidade, que traduz o trabalho do operador.

Portanto, para que a explicação do trabalho restituída pelo ergonomista ao trabalhador tenha inteligibilidade para este último, encontre eco na sua prática, ela deve necessariamente passar pela explicação complexa, colocando em evidência a complexidade do sistema e a complexidade da gestão deste sistema, materializada na atividade do trabalhador. 
Para que se teça algumas considerações, faz-se necessário que se retome as hipóteses apresentadas anteriormente:

- Parte-se do princípio que haja uma associação tácita entre a AET e a Teoria da Complexidade (hipótese geral);

- Demonstrar que a AET é um instrumento para explicitar a complexidade do sistema formado pela situação de trabalho agrícola familiar (hipótese secundária).

Pelo desenrolar do trabalho efetuado nas jornadas, pôde-se demonstrar que ambas as hipóteses foram comprovadas. Ao se optar pela explicação complexa da situação de trabalho como base teórica associada à AET para realizar a análise do trabalho nas UPAFs, pôde-se explicitar a complexidade da situação de trabalho para o próprio agricultor, colocando em evidência as regulações e os compromissos que ele elabora para dar conta da gestão desta complexidade. Os resultados alcançados pela formação-ação confirmam também a afirmação proposta na hipótese secundária.

Dessa forma, a AET permitiu restituir ao agricultor uma visão complexa deste trabalho, ajudando-o no enriquecimento de sua representação tanto individual quanto coletiva, baseada no trabalho real. Com isso, conseguiu-se fortalecer sua posição como ator do projeto de desenvolvimento de sua unidade de produção, tornando-o mais capacitado para trazer para este processo o ponto de vista do trabalho real.

Como uma das etapas da AET passa pela co-construção, entre o ergonomista e o(s) operador(es), de uma representação do trabalho baseada no trabalho real, verifica-se que a explicação do trabalho passa necessariamente por uma visão complexa. O trabalho real é complexo e a AET consegue mostrar esta complexidade (embora nunca de forma exaustiva). Logo, tem-se o pensamento de que a ergonomia deve se distanciar da explicação simplificadora do fenômeno situação de trabalho e aproximar-se cada vez mais de uma visão complexa deste fenômeno.

Acredita-se, por outro lado, ter conseguido demonstrar a associação tácita entre a AET e a teoria da complexidade através da apresentação e discussão dos resultados das crônicas de ação, assim como através da discussão a respeito das ações de antecipação, dos eventos relacionados à auto-organização, à endo-exocausalidade e aos eventos relacionados à recursividade.

Para não deixar dúvida a respeito da pertinência da associação entre a AET e a Teoria da Complexidade, procedeu-se à discussão dos treze princípios de inteligibilidade de um 
paradigma de complexidade, relacionando-os aos resultados obtidos através da AET do agricultor familiar.

Assim, julga-se que, a partir do que foi exposto no trabalho de tese, a associação entre a AET e a Teoria da Complexidade deixará de ser tácita, assumindo explicitamente a existência de uma proximidade teórica entre elas. Ressalte-se, portanto, a necessidade de aproximação teórica da ergonomia com a Teoria da Complexidade.

Para os ergonomistas, em suas intervenções, esta tese pode lhes auxiliar a construir uma explicação complexa do fenômeno trabalho, deixando-os assim mais próximos do trabalho real, fazendo com que encontrem eco na prática dos trabalhadores. Esta postura facilitará inclusive a construção social que é tecida pelo ergonomista ao longo de uma intervenção ergonômica.

\subsection{Uma engenharia}

No âmbito da engenharia, as contribuições da Teoria da Complexidade são de diferentes ordens, uma vez que há questões que se situam em níveis mais restritos, como o desenvolvimento de materiais e de produtos, e outras que se situam em níveis mais amplos, como o desenvolvimento de um serviço à população que considere as necessidades de mobilidade, por exemplo. Ainda, há níveis de concepção e de projeto que são ainda mais abrangentes, uma vez que podem ter impactos em níveis locais, e mesmo globais, como as questões ligadas à produção e consumo de energia, tendoem vista uma perspectiva de longo prazo, sustentável. Em todos os níveis é possível e desejável que se trate dos projetos, sua implantação e sua manutenção com um olhar complexo; uma vez que os projetos de engenharia, se não partirem de uma visão mais integrativa, podem trazer consequências indesejadas, externalidades negativas, que podem ter impactos significativos na vida das pessoas, no ambiente e na economia. Por isso, a integração de diferentes racionalidades que se interligam, que permita a constituição e o enriquecimento de uma perspectiva dialógica, que permita integrar pontos de vista distintos e divergentes pode ser muito profícua se pensarmos em termos do futuro da produção, do trabalho e do próprio desenvolvimento da sociedade.

Retoma-se aqui a questão, levantada anteriormente, da "cientifização da engenharia", que leva à primazia de certos tipos de racionalidade (e.g., instrumental, teleológica), que embora sejam legítimas e desejáveis, não precisam necessariamente excluir outras (e.g., comunicativa, axiológica, subjetiva). Morin explica que o desenvolvimento da ciência ocidental, nos séculos XVI e XVII, constituiu uma busca de racionalidade (em oposição a explicações mitológicas e religiosas). 
No século XVIII, os sucessos da física permitiram conceber um universo determinista totalmente inteligível ao cálculo, transformando a racionalidade em um racionalismo que eliminava toda desordem e toda subjetividade. Assim, a razão tornou-se "[...] o grande mito unificador do saber, da ética e da política [...]” (MORIN, 2010, p. 159) e, no princípio da razão há o princípio utilitário da economia.

A partir disso, tudo aquilo que resistia à redução “[...] passava pela trituradora do princípio de economia-eficácia [...]” (MORIN, 2010, p. 160), instituindo nas sociedades ocidentais uma racionalização instrumental em que eficácia e rendimento parecem trazer a realização da racionalidade social. Pode-se dizer, segundo o autor, que a industrialização (MORIN, 2010; 2015a), a urbanização (MORIN, 2015b), a burocratização (MORIN, 2011a), a tecnologização (MORIN, 2010) se efetuaram segundo os princípios da racionalização, ou seja, da manipulação do social pelos princípios de ordem, de economia e de eficácia (MORIN, 2010).

Sinteticamente, busca-se explicar como Morin inicia o desenvolvimento de uma noção complexa de racionalidade. Para tanto, utiliza-se o exemplo da racionalização industrial, que começou por considerar o trabalhador não como pessoa, mas como força física de trabalho.

No interior das empresas, as primeiras racionalizações do trabalho foram decomposições puramente físicas e mecânicas dos gestos eficazes, ignorando voluntária e sistematicamente o trabalhador. O processo de desumanização do trabalho só desacelerou quando se percebeu que "um resíduo racional denominado fator humano" poderia aumentar o rendimento. A partir desse "resíduo", desenvolvem-se com o tempo ideias como a participação do trabalhador, a cogestão e a autogestão. Apesar das críticas ao uso e à implementação dessas ideias (e.g., ANTUNES; ALVES, 2004; TRAGTENBERG, 2005) e de que elas só eram consideradas "racionais" se aumentassem a economia, o rendimento, a ordem, Morin (2010) observa que ocorre a reintrodução (parcial) do trabalhador. Assim, cada progresso da racionalidade fez-se em reação à racionalização a partir da reintrodução do aparentemente irracional: o sujeito. É a partir dessa ideia que Morin (2010) afirma o surgimento de uma crise da razão, que é interna, nascida da revolta da racionalidade contra a racionalização.

Morin propõe a ideia de razão aberta, em oposição a toda razão absoluta, autossuficiente e fechada, que rejeita tudo o que não está submetido ao princípio de economia e eficácia. A razão aberta é evolutiva, ou seja, “[...] não progride de forma contínua e linear, como julgava o antigo racionalismo, mas por mutações e reorganizações profundas” (MORIN, 2010, p. 167), e nos leva a uma forma de racionalidade complexa. 
Como perspectiva, pode-se, primeiramente, reconhecer a existência de diferentes racionalidades que podem e deveriam influenciar o pensamento da engenharia, como por exemplo:

- Racionalidade instrumental/teleológica: que está ligada à efetividade da ação em relação aos fins. É orientada pragmaticamente para alcançar objetivos e maximizar o valor utilitário (HORKHEIMER, 1976; WEBER, 1987);

- Racionalidade comunicativa: é baseada na dialogicidade e na reciprocidade dos relacionamentos com o outro (VIZEU, 2005). Isso significa que os atores da sociedade buscam alcançar um entendimento comum e coordenar suas ações com base em argumentos fundamentados, consenso e cooperação. Esse tipo de racionalidade se manifesta no consenso resultante da comunicação intersubjetiva mediada por valores pessoais, interesses, conceitos e linguagem (HABERMAS, 1984);

- Racionalidade axiológica: está associada ao critério de justiça da ação em relação aos valores no mundo social; permite a compreensão do outro como portador de valores e julgamentos morais (DAMERON, 2005). Por exemplo, um trabalho sustentável, imbuído de significado e construído sobre relações de confiança e cooperação, seria impossível na ausência de uma perspectiva axiológica que vá além do valor econômico (BOLIS; MORIOKA; SZNELWAR, 2017);

- Racionalidade subjetiva ou páthica: refere-se ao desenvolvimento do mundo subjetivo, no qual os processos de construção da identidade ocorrem com base nas experiências vividas e nas relações intersubjetivas (DEJOURS, 2012; SZNELWAR, 2015).

Em segundo lugar, o reconhecimento da existência de diferentes racionalidades é fundamental, mas não é suficiente para entender como integrá-las às ações de engenharia. Assim, com base em Morin (2010, 2015a, 2016), a partir de uma racionalidade da complexidade é possível:

- Reconhecer e articular diferentes racionalidades;

- Reconhecer que o real sempre excede o racional;

- Desenvolver uma racionalidade evolutiva e, com isso, reconhecer sua natureza biodegradável; 
- Desenvolver uma racionalidade dialógica, isto é, que não concebe termos até então considerados antinômicos em oposição absoluta, mas em oposição relativa, em complementaridade, em comunicação, em trocas;

- Conservar a vontade de controle lógico, mas entendendo a racionalidade como atitude crítica, acrescentando-lhe a autocrítica e o reconhecimento dos limites da lógica;

- Reconhecer o irracional, ou seja, desordem, aleatoriedade, violações lógicas; não rejeitar - dialogar com o irracional;

- Reconhecer o a-racional, não se limitando ao dualismo racional-irracional;

- Reconhecer o sobrerracional, pois toda criação e toda invenção comportam algo que a racionalidade pode eventualmente compreender depois, mas nunca antes;

- Entender que a razão não é somente um método, mas também uma aptidão para elaborar sistemas de ideias ${ }^{11}$, mas sistemas que não são dados como definitivamente estabelecidos e que podem ser remodelados ${ }^{12}$.

Enfim, o pensamento complexo de Edgar Morin e de todos aqueles que o adotaram e o desenvolveram permite trazer ao debate questões fundamentais com relação à vida e a importância do sujeito na sociedade. O diálogo com outras áreas do conhecimento, em especial o da psicodinâmica do trabalho que adota uma perspectiva de sujeito oriunda da antropologia psicanalítica também pode ser bastante profícuo, uma vez que no pensamento de Sigmund Freud também estão incluídas, mesmo que haja controvérsias, questões muito próximas das propostas na complexidade, como as da dialógica, de ordem e desordem e, de modo significativo, as incertezas, ainda mais quando se trata do devir dos sujeitos e da humanidade.

Concluindo sem concluir, obrigado Edgar Morin!

\section{Referências}

ANTUNES, Ricardo; ALVES, Giovanni. As mutações no mundo do trabalho na era da mundialização do capital. Educação\&Sociedade, v. 25, n. 87, p. 335-351, 2004.

BEDER, Sharon. Beyond technicalities: Expanding engineering thinking. JournalofProfessional Issues in Engineering Education and Practice, v. 125, n. 1, p. 12-18, 1999.

\footnotetext{
${ }_{11}^{11}$ Pois “[...] uma ideia isolada não tem praticamente existência; só ganha consistência em relação a um sistema que a integre” (MORIN, 2011a, p. 160).

${ }^{12}$ Conforme Morin (2011a, p. 159-162), todo sistema de ideias é simultaneamente fechado e aberto: fechado porque se defende contra e resiste às críticas e refutações externas; aberto porque se alimenta de confirmações e verificações vindas do mundo exterior. Sistemas de prioridade à abertura podem ser denominados teorias, enquanto os que priorizam o fechamento, doutrinas.
} 
BOLIS, Ivan; MORIOKA, Sandra N.; SZNELWAR, Laerte I. Are we making decisions in a sustainable way? A comprehensive literature review about rationalities for sustainable development. Journal of Cleaner Production, v. 145, p. 310-322, 2017.

$\mathrm{CECH}$, Erin A. The (mis) framing of social justice: Why ideologies of depoliticization and meritocracy hinder engineers' ability to think about social injustices. In: LUCENA; Juan C. (ed.).Engineering education for social justice. Dordrecht: Springer, 2013. p. 67-84.

$\mathrm{CECH}$, Erin A. Culture of disengagement in engineering education?.Science, Technology, \& Human Values, v. 39, n. 1, p. 42-72, 2014.

CHRISTENSEN, Steen H.et al. Engineering identities, epistemologies and values: Engineering Education and Practice in Context. Dordrecht: Springer, 2015.

CILLIERS, Paul; PREISER, Rika (ed.). Complexity, difference and identity: An ethical perspective. Berlin: Springer Science \& Business Media, 2010.

CONTI, Thomas V. Crise Tripla do Covid-19: um olhar econômico sobre políticas públicas de combate à pandemia. Working paper. 2020. Disponível em: http://thomasvconti.com.br/pubs/coronavirus/. Acesso em: 3 jun. 2021.

COSTA JUNIOR, Jairo; DIEHL, Jan C.; SECOMANDI, Fernando. Educating for a systems design approach to complex societal problems. Journal of Engineering Design, v. 29, n. 3, p. 65-86, 2018.

DAMERON, Stéphanie. La dualité du travail coopératif. Revue Française de Gestion, n. 5, p. 105-120, 2005.

DEJOURS, Christophe. Por um novo conceito de saúde. Revista Brasileira de Saúde Ocupacional, São Paulo, v. 14, n. 54, p. 7-11, 1986.

DEJOURS, Christophe. Trabalho vivo: trabalho e emancipação. Tomo II. Brasília, DF: Paralelo 15, 2012.

ESCOLA POLITÉCNICA DA USP (POLI-USP). Proposta de Criação de Curso. Habilitação: Engenharia da Complexidade. Programa Permanente de Parceria entre a Escola Politécnica da USP e o Groupe des Écoles Centrale da França. São Paulo:Universidade de São Paulo, 2016.

FAULKNER, Wendy. Nuts and Bolts and People' Gender-Troubled Engineering Identities. Social Studies of Science, v. 37, n. 3, p. 331-356, 2007.

FEENBERG, Andrew. Questioning technology. London: Routledge, 2012.

FINELLI, Cynthia J.; BORREGO, Maura; RASOULIFAR, Golnoosh. Development of a taxonomy of keywords for engineering education research. IEEE Transactions on Education, v. 58, n. 4, p. 219-241, 2015.

FREI, Regina; SERUGENDO, Giovanna D. M.Concepts in complexity engineering. International Journal of Bio-Inspired Computation, v. 3, n. 2, p. 123-139, 2011. 
GRAHAM, Ruth. The global state of the art in engineering education. Massachusetts, USA: Massachusetts Institute of Technology (MIT) Report, 2018.

GUÉRIN, François et al. Compreender o trabalho para transformá-lo: a prática da ergonomia. São Paulo: Blücher, 2001.

GUNTZBURGER, Yoann; PAUCHANT, Thierry C.; TANGUY, Philippe A. Empowering engineering students in ethical risk management: An experimental study. Science and Engineering Ethics, v. 25, n. 3, p. 911-937, 2019.

HABERMAS, Jürgen. Teoria do agir comunicativo: Racionalidade da ação e racionalização social. Tradução de Paulo Astor Soethe. Revisão técnica de Flávio Beno Siebeneichler. São Paulo: WMF Martins Fontes, 1984.

HAGHIGHI, Kamyar. Quiet no longer: Birth of a new discipline. Journal of Engineering Education, v. 94, n. 4, p. 351, 2005.

HEYLIGHEN, Francis. Complexity and self-organization. In: LAPLANTE, Phillip. Encyclopedia of Information Systems and Technology - v. 1. London: CRC Press, 2015. p. 250-259.

HORKHEIMER, Max. Eclipse da razão. São Paulo: Editora da Unesp, 1976.

JESIEK, Brent K. et al. Mapping global trends in engineering education research. International Journal of Engineering Education, v. 27, n. 1, p. 77-90, 2011.

JOHRI, Aditya; OLDS, Barbara M. (ed.). Cambridge Handbook of Engineering Education research. Cambridge: Cambridge University Press, 2014.

JONASSEN, David; STROBEL, Johannes; LEE, ChweeB. Everyday problem solving in engineering: Lessons for engineering educators. Journal of Engineering Education, v. 95, n. 2, p. 139-151, 2006.

LEYDENS, Jon A.; LUCENA, Juan C. Engineering justice: Transforming engineering education and practice. Nova Jersey, USA: John Wiley \& Sons, 2018.

LUCENA, Juan (ed.). Engineering education for social justice: Critical explorations and opportunities. Dordrecht: Springer, 2013.

MCKENNA, Ann F.; FROYD, Jeffrey; LITZINGER, Thomas. The complexities of transforming engineering higher education: Preparing for next steps. Journal of Engineering Education, v. 103, n. 2, p. 188, 2014.

MEIJERS, Anthonie W. et al. Philosophy of technology and engineering sciences. Oxford: North Holland/Elsevier, 2009.

MICHELFELDER, Diane P.; MCCARTHY, Natasha; GOLDBERG, David E. (ed.). Philosophy and engineering: Reflections on practice, principles and process. Berlin: Springer Science \& Business Media, 2017. 
MICHELFELDER, Diane P.; NEWBERRY, Byron; ZHU, Qin. Philosophy and engineering. Berlin: Springer International Pu, 2017.

MINAI, Ali A.; BRAHA, Dan; BAR-YAM, Yaneer. Complex engineered systems: A new paradigm. In: BRAHA, Dan; MINAI, A. A.; BAR-YAM, Y. Complex Engineered Systems. Dordrecht: Springer, 2006. p. 1-21.

MITCHAM, Carl. Thinking through technology: The path between engineering and philosophy. Chicago: University of Chicago Press, 1994.

MOLINIER, Pascale. O trabalho e a psique: uma introdução à psicodinâmica do trabalho. Brasília, DF: Paralelo, 2013.

MONTEDO, Uiara B. Ergonomia e Complexidade no Trabalho Agrícola Familiar: um olhar sobre a relação tácita entre a Teoria da Complexidade e a Ergonomia da Atividade. Beau Bassin: Novas Edições Acadêmicas, 2017.

MONTEDO, Uiara B.; SZNELWAR, Laerte I. Análise ergonômica do trabalho agrícola familiar na produção de leite. Production, v. 18, n. 1, p. 142-154, 2008.

MORIN, Edgar. Ciência com consciência. 14. ed. Rio de Janeiro: Bertrand Brasil, 2010.

MORIN, Edgar. O método 4: as ideias. 5. ed. Porto Alegre: Sulina, 2011a.

MORIN, Edgar. Os sete saberes necessários à educação do futuro. 2. ed. São Paulo: Cortez, $2011 b$.

MORIN, Edgar. O método 5: a humanidade da humanidade. 5. ed. Porto Alegre: Sulina, 2012.

MORIN, Edgar. Introdução ao pensamento complexo. 5. ed. Porto Alegre: Sulina, 2015a.

MORIN, Edgar. O método 2: a vida da vida. 5. ed. Porto Alegre: Sulina, 2015b.

MORIN, Edgar. O método 3: o conhecimento do conhecimento. 5. ed. Porto Alegre: Sulina, $2015 \mathrm{c}$.

MORIN, Edgar. O método 1: a natureza da natureza. Porto Alegre: Sulina, 2016.

MORIN, Edgar. O método 6: ética. 5. ed. Porto Alegre: Sulina, 2017a.

MORIN, Edgar. A cabeça bem-feita: repensar a reforma, reformar9 o pensamento. Rio de Janeiro: Bertrand Brasil, 2017b.

MORIN, Edgar; LE MOIGNE, Jean-Louis. A Inteligência da Complexidade. Rio de Janeiro: Fundação Peirópolis, 2000.

NATIONAL ACADEMY OF ENGINEERING (NAE). Call for Engineering Action on the COVID-19 Crisis. Disponível em: https://www.nae.edu/230195/Call-for-EngineeringResponse-to-the-COVID19-Crisis. Acessoem: 3 maio2020. 
PAWLEY, Alice L. Learning from small numbers: Studying ruling relations that gender and race the structure of US engineering education. Journal of Engineering Education, v. 108, n. 1, p. 13-31, 2019.

PIQUEIRA, José R. C. Engenharia da Complexidade em Edgar Morin. Estudos Avançados, São Paulo, v. 32, n. 94, p. 363-370, 2018.

POEL, Ibo V. D.; GOLDBERG, David E. (ed.). Philosophy and engineering: An emerging agenda. Berlin: Springer Science \& Business Media, 2010.

RADCLIFFE, David F. Shaping the discipline of engineering education. Journal of Engineering Education, v. 95, n. 4, p. 263, 2006.

REUBEN, Ernesto; SAPIENZA, Paola; ZINGALES, Luigi. How stereotypes impair women's careers in science. Proceedings of the National Academy of Sciences, v. 111, n. 12, p. 44034408, 2014.

RILEY, Donna. Engineering and social justice: Synthesis Lectures on Engineers, Technology, and Society. San Rafael: Morgan\&Claypool Publishers, 2008.

SIGAHI, Tiago F. A. C.; SZNELWAR, Laerte I. Restricted and General Complexity in Ergonomics. In: BLACK, N. L.; NEUMANN, W. P.; NOY I. (ed.). Lecture Notes in Networks and Systems - Vol. I: Systems and Macroergonomics. Cham: Springer, 2021. p. 792-798.

STOJANOV, Zeljko; DOBRILOVIC, Dalibor; ZORIC, Amara. Solving Problems in a Physical Laboratory for Computer Networks and Data Security: a conceptual frameworkwith students' experiences. InternationaL Journal of Engineering Education, v. 32, n. 6, p. 25172530, 2016.

SZNELWAR, Laerte I. Quando trabalhar é ser protagonista e o protagonismo do trabalho. São Paulo: Blucher, 2015.

SZNELWAR, Laerte I.; UCHIDA, Seiji; LANCMAN, Selma. A subjetividade no trabalho em questão. Tempo Social, São Paulo,v. 23, n. 1, p. 11-30, 2011.

SZNELWAR, Laerte I.et al.Brumadinho: entre a prudência ea probabilidade, a tragédia. Revista Brasileira de Medicina do Trabalho, São Paulo,v. 17, n. 1, p. 4-12, 2019.

TERTRE, Christian D. É conomie servicielle et travail: contribution théoriqueau développement «d'une économie de lacoopération». Travailler, n. 1, p. 29-64, 2013.

TONSO, Karen L. Teams that work: Campus culture, engineer identity, and social interactions. Journal of Engineering Education, v. 95, n. 1, p. 25-37, 2006.

TRAGTENBERG, Maurício. Administração, Poder e Ideologia. São Paulo: Editora UNESP, 2005. 
TSOUKAS, Haridimos. Don't simplify, complexify: From disjunctive to conjunctive theorizing in organization and management studies. Journal of Management Studies, v. 54, n. 2, p. 132-153, 2017.

VIZEU, Fábio. Ação comunicativa e estudos organizacionais. Revista de Administração de Empresas, São Paulo,v. 45, n. 4, p. 10-21, 2005.

WEBER, Max. A ética protestante e o espírito do capitalismo. São Paulo: Companhia das Letras, 1987.

WISNER, Alain. Understanding problem building: ergonomic work analysis. Ergonomics, v. 38, n. 3, p. 595-605, 1995.

ZILBOVICIUS, Mauro; PIQUEIRA, José R. C.; SZNELWAR, Laerte I99. Complexity engineering: New ideas for engineering design and engineering education. Anais da Academia Brasileira de Ciências, Rio de Janeiro, v. 92, n. 3, 2020. 